\title{
Toll-Like Receptor 4, but Not Neutrophil Extracellular Traps, Promote IFN Type I Expression to Enhance Th2 Responses to Nippostrongylus brasiliensis
}

\author{
Christophe Pellefigues', Shiau-Choot Tang ${ }^{1}$, Alfonso Schmidt', Ruby F. White', \\ Olivier Lamiable ${ }^{1}$, Lisa M. Connor ${ }^{1}$, Christiane Ruedl ${ }^{2}$, Jurek Dobrucki ${ }^{3}$, \\ Graham Le Gros ${ }^{1}$ and Franca Ronchese ${ }^{1 *}$ \\ ${ }^{1}$ Malaghan Institute of Medical Research, Wellington, New Zealand, ${ }^{2}$ School of Biological Sciences, Nanyang Technological \\ University, Singapore, Singapore, ${ }^{3}$ Faculty of Biochemistry, Biophysics and Biotechnology, Department of Cell Biophysics, \\ Jagiellonian University, Kraków, Poland
}

OPEN ACCESS

Edited by: Joao P. B. Viola, Instituto Nacional de Câncer (INCA), Brazil

Reviewed by:

Claudia Ida Brodskyn, Centro de Pesquisa Gonçalo Moniz-FIOCRUZ/BA, Brazil John P. Vasilakos,

3M Company, United States

${ }^{*}$ Correspondence: Franca Ronchese fronchese@malaghan.org.nz

Specialty section: This article was submitted to

Molecular Innate Immunity,

a section of the journal

Frontiers in Immunology

Received: 21 August 2017 Accepted: 02 November 2017 Published: 16 November 2017

Citation:

Pellefigues C, Tang S-C, Schmidt A, White RF, Lamiable O, Connor LM,

Ruedl C, Dobrucki J, Le Gros G and Ronchese F (2017) Toll-Like Receptor

4, but Not Neutrophil Extracellular

Traps, Promote IFN Type I Expression to Enhance Th2 Responses to Nippostrongylus brasiliensis.

Front. Immunol. 8:1575. doi: 10.3389/fimmu.2017.01575
The induction of Th2 responses is thought to be multifactorial, and emerge from specific pathways distinct from those associated with antagonistic antibacterial or antiviral Th1 responses. Here, we show that the recognition of non-viable Nippostrongylus brasiliensis $(\mathrm{Nb})$ in the skin induces a strong recruitment of monocytes and neutrophils and the release of neutrophil extracellular traps (NETs). Nb also activates toll-like receptor 4 (TLR4) signaling with expression of Ifnb transcripts in the skin and the development of an IFN type I signature on helminth antigen-bearing dendritic cells in draining lymph nodes. Co-injection of $\mathrm{Nb}$ together with about 10,000 Gram-negative bacteria amplified this TLR4-dependent but NET-independent IFN type I response and enhanced the development of Th2 responses. Thus, a limited activation of antibacterial signaling pathways is able to boost antihelminthic responses, suggesting a role for bacterial sensing in the optimal induction of Th2 immunity.

Keywords: Nippostrongylus brasiliensis, helminth, dendritic cells, toll-like receptor 4, IFN-I, neutrophil extracellular traps, Th2 response, skin immunity

\section{INTRODUCTION}

Diverse immune responses have been associated with different classes of pathogen or insult, and with the specialization of $\mathrm{CD} 4^{+} \mathrm{T}$ helper cells toward the secretion of a certain set of effector cytokines: Th1 cells secreting Interferon- $\gamma($ IFN $\gamma)$ are generated in antitumoral, antibacterial, and anti-“intracellular pathogen" responses, Th2 cells secreting interleukin 4 (IL4), IL5, and/or IL13 are generated in anti-venom/toxin/irritant and anti-macroparasite (including helminths and ticks) responses, and Th17/22 cells secreting IL17 or IL22 are generated upon antifungal and antibacterial responses (1-3).

Tissue resident dendritic cells (DCs) are critical for the priming of antigen specific $\mathrm{T}$ cell responses. They are able to shape the polarization of adaptive immunity toward a Th1, Th2, or Th17 response by interpreting signals from their environment (1). While the sensing of viral and bacterial nucleic acids by intracellular Pattern Recognition Receptors, and of bacterial lipopolysaccharides (LPS) by Toll-like receptor 4 (TLR4) have been shown to induce the development of strong Th1 responses, 
a consensus signal required to induce the development of Th2 immune responses has not been identified. Several types of signals can participate in inducing a Th2 response including, but not limited to, tissue derived cytokines and alarmins such as TSLP, IL25, and IL33, an innate "third party" source of IL4, the activity of specific proteases or phospholipases, some macroparasite glycans or glycolipid motifs, and the detection of extremely low amounts of LPS $(1,3-7)$. Understanding the signals that govern the development of Th2 responses is of uttermost importance considering that helminths potentially affect around $25 \%$ of the world population $(8,9)$ while allergic diseases can affect more than $30 \%$ of the population (10), mainly in areas where helminthiases are not endemic.

We unexpectedly identified that the development of Th2 responses to the prototypical helminth Nippostrongylus brasiliensis $(\mathrm{Nb})$ is partly dependent on IFN type I (IFN-I) signaling (11). It has also been shown very recently that IFN-I is important for the initiation of Th2 responses to Schistosoma mansoni and House dust mite (HDM) by DCs (12). Indeed, 2 days after the injection of non-viable AF488-labeled $\mathrm{Nb}$ into the ear dermis, AF488 ${ }^{+}$DCs infiltrating the draining lymph nodes (dLNs) showed a strong transcriptomic IFN-I signature. These AF488 ${ }^{+}$ DCs also showed a phenotypic IFN-I signature as demonstrated by their expression of several IFN-I-dependent cell surface markers including bone marrow (BM) stromal antigen 2 (BST2, or CD317). Neutralizing IFN-I signaling with $\alpha$ IFNAR1 antibodies was able to diminish the expansion of IL4-secreting $\mathrm{CD} 4^{+} \mathrm{T}$ cells in response to $\mathrm{Nb}$ (11). As IFN-I signaling is generally associated with the development of antiviral, antibacterial, or autoimmune responses (13-15), and with DC activation and maturation (16-21), we sought to identify by which mechanisms $\mathrm{Nb}$ could induce an IFN-I response.

The release of endogenous oxidized DNA during cell death or neutrophil extracellular traps (NETs) secretion is strongly immunogenic and interferogenic in various pathophysiological contexts (22-25). As neutrophils are important for the immune response to $\mathrm{Nb}$ (26-28), we investigated whether $\mathrm{Nb}$ injection induced the secretion of NETs in the skin. To this end, we used a very controlled and defined system utilizing non-viable L3 Nb larvae injected into the ear dermis (29). This enabled us to monitor the development of the immune response in local tissue and auricular dLNs in the absence of potential interfering factors such as local tissue damage or infection-related systemic effects.

We show that the injection of non-viable L3 Nb larvae into the ear dermis induces recruitment of neutrophils undergoing NETosis around the worms. Surprisingly, NET digestion or depletion of neutrophils were not sufficient to diminish the IFN-I signature on $\mathrm{AF} 488^{+}$DCs. Interestingly, expression of IFN-I in the skin, and the IFN-I-dependent upregulation of BST2 on dLN DCs, required expression of TLR4. Consistent with this observation, adding Gram-negative bacteria to $\mathrm{AF} 488^{+} \mathrm{Nb}$ before injection increased the expression of BST2 on AF $488^{+}$DCs in dLN, and the magnitude of the resulting Th2 response. These findings strongly suggest that metazoan parasite TLR4 ligands, originating from their associated microorganisms and/or also from their cuticle glycans $(7,30)$, induce the secretion of IFN-I to enhance DC maturation and the development of specific Th2 responses.

\section{MATERIALS AND METHODS}

\section{Mice and Treatments}

Seven- to 10-week-old female C57BL/6J, SiglecH-DTR (31), TLR2 KO (32), and TLR4 KO (32) mice were bred and housed in specific pathogen-free conditions at the Malaghan Institute of Medical Research Biomedical Research Unit. All experimental protocols were approved by the Victoria University of Wellington Animal Ethics Committee (Permit 2014R17M) and performed according to Institutional guidelines.

Nippostrongylus brasiliensis infective L3 larvae $(\mathrm{Nb})$ were collected, washed in sterile PBS, killed by three freeze-thaw cycles, and injected intradermally (i.d.) into the ear pinna of anesthetized mice as previously described (29). "Low Endotoxin" Nb preparations (LE-Nb) were achieved by adding five extra washing steps to the preparation. Endotoxin content was quantified using the LAL Chromogenic Endotoxin quantitation kit (Pierce) and was $<5 \mathrm{EU} / \mathrm{mL}$. Nb sterilization was achieved by antibiotic treatment as previously described (27). In some experiments, $\mathrm{Nb}$ was labeled using Alexa Fluor 488 (AF488) succinimidyl ester dyes (Molecular Probes) as described previously (11). To prepare $\mathrm{Nb}$ supernatant $(\mathrm{SN})$, Nb suspensions were left to sediment for $5 \mathrm{~min}$ at room temperature (RT), and SN collected.

To block IFN-I signaling in vivo, mice were treated i.d. with $250 \mu \mathrm{g}$ MAR1-5A3 (blocking anti-mouse IFN-alpha and beta receptor 1 antibody, anti-IFNAR1) or isotype control (MOPC21) given with $\mathrm{Nb}$ on day 0 . The same antibody dose was given again on day 2 by intraperitoneal (i.p.) injection. "In Vivo Plus" MAR1-5A3 and MOPC-21 were from BioXCell (West Lebanon, NH, USA).

To deplete plasmacytoid DCs (pDCs), SiglecH-DTR mice were given $25 \mathrm{ng} / \mathrm{g}$ diphtheria toxin (DT, Sigma) i.p. 1 day before $\mathrm{Nb}$ injection. In all experiments, flow cytometry analysis of spleen cells confirmed $>95 \%$ depletion of pDCs, identified as CD $11 \mathrm{~b}^{-}$ $\mathrm{CD}_{11 \mathrm{c}^{+}} \mathrm{B}_{220^{+}} \mathrm{Ly}_{6 \mathrm{C}^{+}} \mathrm{BST}^{+}$cells, compared to DT-untreated controls. Neutrophils were depleted by injecting $0.5 \mathrm{mg}$ antiLy6G antibody or $200 \mu \mathrm{g}$ anti-Gr1 antibody versus the same amount of their isotype control (IA8 or RB6-8C5, respectively, InVivoPlus, BioXCell) i.p. 1 day before and on the day of $\mathrm{Nb}$ injection. Depletion was assessed in skin by enumerating neutrophil infiltration as $\mathrm{CD}_{4} 5^{+} \mathrm{CD} 11 \mathrm{~b}^{+}$Ly6C $^{\text {int }} \mathrm{Ly} 6 \mathrm{~B}^{+}$cells $(50-70 \%$ depletion) or $\mathrm{CD}_{4} 5^{+} \mathrm{CD}_{11 \mathrm{~b}^{+}} \mathrm{Ly}_{6 \mathrm{G}}{ }^{+}$cells (>95\% depletion). To digest NETs, mice were injected with 2,000 U DNase I i.d. (Roche) together with $\mathrm{Nb}$, followed by 2,000 U i.p. every $12 \mathrm{~h}$ until the end of the experiment. NET digestion was qualitatively confirmed by microscopy at $2 \mathrm{~h}$ after DNase I injection $(33,34)$.

\section{Quantitative Reverse Transcription PCR (RT-qPCR)}

Ears were collected at the indicated times and stored in RNALater (Invitrogen) at $4^{\circ} \mathrm{C}$. Tissue was cut into small pieces with scissors and homogenized using TissueLizer II (Qiagen) and RNA was extracted with Trizol (Invitrogen) following the supplier's instructions. cDNA was synthetized using the High capacity RNAto-cDNA kit (Applied Biosystems). RT-qPCR was performed using SYBR Green Master Mix and the following primers: Beta 
Actin (F:5' CTAAGGCCAACCGTGAAAAG, R:5' ACCAGA GGCATACAGGGACA), Ifnk (F:5' CCGCCCATCCAATCTCT GAA, R:5' GGAAAGCCGGTCATGGTACT), Ifnb1 (F:5' GCACTGGGTGGAATGAGACT, R: 5'-AGTGGAGAGCAGTT GAGGACA), and Ifna (F: 5'-TCTGATGCAGCAGGTGGG, R: 5'-AGGGCTCTCCAGACTTCTGCTCTG) to amplify all Ifna species (16), using a QuantStudio 7 (Applied Biosystems) and following the manufacturer's guidelines. Transcript levels are expressed as the ratio of $2^{-\Delta \mathrm{CT}}$ (Transcript of interest) $/ 2^{-\Delta \mathrm{CT}}$ (Beta Actin) and normalized by comparison to pertinent experimental controls.

\section{Cell preparations and Flow Cytometry}

For DC preparations, auricular dLNs were harvested and digested for $30 \mathrm{~min}$ at $37^{\circ} \mathrm{C}$ in IMDM (Gibco) containing $100 \mu \mathrm{g} / \mathrm{mL}$ DNase I and $100 \mu \mathrm{g} / \mathrm{mL}$ Liberase TL (Roche). For T cell preparations, LNs were passed through a $70-\mu \mathrm{m}$ cell strainer (Falcon). For skin cell preparations, ears were split into the dorsal and ventral layers, and then minced in Accutase (Stemcell) containing 3 $\mathrm{U} / \mathrm{mL}$ Dispase II, $100 \mu \mathrm{g} / \mathrm{mL}$ DNAse I, and $100 \mathrm{ng} / \mathrm{mL}$ Liberase TM (Roche) for $30 \mathrm{~min}$ at $37^{\circ} \mathrm{C}$.

Peripheral blood leukocytes were harvested by cheek puncture and red blood cells were lysed in an ammonium chloride/TRIS buffer, as detailed elsewhere (35). Single cell suspensions were filtered on 70- $\mu \mathrm{m}$ nylon mesh cell strainers (Falcon) and blocked for $15 \mathrm{~min}$ at $4^{\circ} \mathrm{C}$ in FACS Buffer (PBS $1 \%$ bovine serum albumin $0.05 \% \mathrm{NaN}_{3}$ ) containing anti-mouse CD16/CD32 from affinity purified 2.4G2 hybridoma SN. Cells were then stained in FACS Buffer for $20 \mathrm{~min}$ at $4^{\circ} \mathrm{C}$ with an optimized concentration of fluorophore-conjugated antibodies.

For intracellular cytokine staining, cells were cultured in complete IMDM containing 10\% Fetal Calf Serum (FCS) and penicillin/streptomycin (all from Gibco) and stimulated with Phorbol 12-Myristate 13-Acetate $(50 \mathrm{ng} / \mathrm{mL})$ and Ionomycin $\left(1 \mu \mathrm{g} / \mathrm{mL}\right.$ ) for $5 \mathrm{~h}$ at $37^{\circ} \mathrm{C}$ in the presence of GolgiStop (BD Bioscience). After surface staining, cells were fixed and permeabilized with the Cytofix/Cytoperm kit (BD Bioscience) and stained intracellularly.

The fluorescent antibodies used were specific for CD11c (HL3), CD86 (GL1), MHCII (M5/114), CD326 (G8.8), CD4 (RM4-5), CD3 (145-2C11), CD103 (M290), IL4 (11B11), IFNg (XMG1.2), and CD44 (IM7; all from BD); IL10 (JES5-16E3), CD8a (53-6.7), CD11b (M1/70), CD45 (30-F11), CD64 (X54-5/7.1FC), Ly6C (HK1.4), Ly6G (IA8), CD317 (BST2, clone 927) from BioLegend; IL17A (eBio17B7) and B220 (RA3-6B2; both from eBioscience); Ly6B.2 (7/4) from Thermofischer. IL4-AmCyan expression was quantified with a 504/12 filter after excitation at $445 \mathrm{~nm}$. Nonviable cells and doublets were identified and excluded using DAPI or LIVE/DEAD staining (Molecular Probes). Compensations were performed using OneComp eBeads (Invitrogen) as single stained positive controls and fluorescence minus one (FMO) controls were used to set background expression. Flow cytometry was performed on a BD LSRII or LSR Fortessa SORP flow cytometer with FacsDiva 6.1.1 software (Becton Dickinson). Analyses were conducted using FlowJo vX (Tree Star) and the represented values of expression intensity are the geometric means of fluorescence intensity (mfi).

\section{Cell Culture}

Human Embryonic Kidney 293 (HEK) cell lines engineered to report NF- $\mathrm{KB}$ activation with the secretion of an optimized alkaline phosphatase were used to study the signaling pathways activated by Nb. HEK-Blue cells expressing murine TLR2, TLR4, TLR7, or TLR9, and their respective control cell lines (Null1, Null2, Null1-v, Null2-k) were cultured in triplicate in 96 well plates at $50,000 /$ well, and stimulated $\mathrm{O} / \mathrm{N}$ at $37^{\circ} \mathrm{C}$ with either 100 $\mathrm{Nb}$ or the appropriate positive controls. Reporter expression was assessed using QuantiBlue medium (InvivoGen) following manufacturer's instructions. Absorbance at $640 \mathrm{~nm}$ was measured on a spectrophotometer (Helios Gamma, ThermoScientific). Data from each reporter cell line were expressed as ratio of the means of stimulated versus unstimulated cultures.

Primary BM cells were harvested by flushing femurs' content using medium. One million cells were cultured in RPMI and $10 \%$ FCS (Gibco) for $24 \mathrm{~h}$ at $37^{\circ} \mathrm{C}$, in the presence of $10 \mu \mathrm{g} / \mathrm{mL}$ InVivoPlus mouse IgG1 (MOPC1) or anti-IFNAR1 (MAR-5A3) from Bio X Cell (Lebanon, NH, USA). Cultures were stimulated with HDM whole bodies (Greer) at $100 \mu \mathrm{g} / \mathrm{mL}$, or $10-200 \mathrm{Nb}$, or $10 \mu \mathrm{g} / \mathrm{mL}$ low-endotoxin Poly(I:C) (Invitrogen). Escherichia coli (E. coli) MG1655 was grown in Luria Broth (Invitrogen) at $37^{\circ} \mathrm{C}$, quantified by OD, harvested at exponential growth phase, and fixed in $1 \%$ formalin.

\section{Microscopy}

One hundred and fifty AF488-labeled $\mathrm{Nb}$ were injected into the ear dermis in $30 \mu \mathrm{l}$ of sterile PBS. After different times, mice were euthanized and hair was removed with a hair removal cream (Veet) before harvesting the ears. The ear dorsal and ventral parts were split and fixed in $4 \%$ formalin (Sigma) for $30 \mathrm{~min}$, washed in PBS, permeabilized and blocked in PBS with $0.3 \%$ Triton X100 (PBS-T) $5 \%$ Donkey serum and 2.4G2 hybridoma SN at RT for $30 \mathrm{~min}$. The same buffer was used for antibody staining: primary antibody staining was performed using $5 \mu \mathrm{g} / \mathrm{mL}$ of goat anti human/mouse MPO (R\&D, AF3667), 1/500 rabbit anti-Histone H3 citrulline $(\mathrm{R} 2+\mathrm{R} 8+\mathrm{R} 17, \mathrm{ab} 103)$ or 1/100 rabbit anti-mouse Neutrophil elastase (ab21595, both from Abcam) for $2 \mathrm{~h}$ at RT or overnight at $4^{\circ} \mathrm{C}$. Samples were washed five times in PBS-T and then stained for $1 \mathrm{~h}$ using 1/500 donkey anti-goat AF594 (ab140150) and/or 1/500 donkey anti-rabbit AF647 (ab181347, both from Abcam). After five washes, tissue was mounted under a coverslip in Fluoromount (Sigma) and recorded using a Confocal Laser Scanning microscope FV1200-IX83 (Olympus). Image analysis and tri-dimensional reconstructions were done with the Fiji version of Image $\mathrm{J}$ and the help of a $3 \mathrm{D}$ viewer plugin to juxtapose z-stacks $(36,37)$.

\section{Statistical Analysis}

Statistical analyses were performed using Prism 7.0 (GraphPad). The distribution of the data groups was always assessed using a Shapiro-Wilk test for normality. Data groups were compared using one way ANOVA with a Tukey's multiple comparison test for experiments following a normal distribution, or using the Mann-Whitney tests, or, when more than three independent groups were considered, a Kruskal-Wallis with a Dunn's multiple comparison test for experiments whose data points were 
not following a normal distribution. In all cases, a two-tailed $p$ value $<0.05$ was considered as threshold for significance. Mean and SEM are shown in all graphs.

\section{RESULTS}

\section{The Majority of Cells Taking up Nb Material in the Skin at $24 \mathrm{~h}$ Are Neutrophils and Inflammatory Monocytes}

Stage 3 (L3) larvae from the helminth $\mathrm{Nb}$ can infect rodents by penetrating their skin barrier. To study the development of antihelminth Th2 responses in skin we used a simplified model involving injection of non-viable $\mathrm{Nb}$ into the ear dermis of mice $(29,38)$. Nb injection induced a quick and transient neutrophilia in the blood (Figure 1A) and an accumulation of $\mathrm{CD}_{4} 5^{+}$leukocytes in the ear dermis comprising mainly CD11b ${ }^{\text {hi }} \mathrm{Ly} 6 \mathrm{G}^{+}$ neutrophils and CD $11 b^{\text {hi }}$ Ly6G $^{-}$Ly6C $^{\text {hi }}$ inflammatory monocytes at $24 \mathrm{~h}$ (Figure 1B).
The reactive amines in the cuticle of $\mathrm{Nb}$ larvae can be stained covalently with the succinimidyl ester AF488, to generate AF $488^{+} \mathrm{Nb}$ larvae $(11,38) .24 \mathrm{~h}$ after AF488 ${ }^{+} \mathrm{Nb}$ injection, approximately $90 \%$ of the cells that had taken up AF488 in the dermis were neutrophils and inflammatory monocytes. Indeed, the majority of these two cell types stained positively for AF488 (Figures 1C,D). Of note, AF488 fluorescence was consistently brighter in monocytes than neutrophils, which might be due to different phagocytosis rates, dye stability, or apoptosis of these cell populations.

These observations show that neutrophils and inflammatory monocytes are recruited early to the ear dermis to interact with non-viable $\mathrm{Nb}$.

\section{Injection of Non-viable $\mathrm{Nb}$ Induces NETosis in the Dermis}

In order to visualize the early events in the interaction of non-viable $\mathrm{Nb}$ with infiltrating leukocytes, we carried out a
A

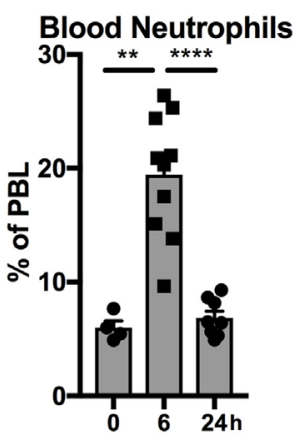

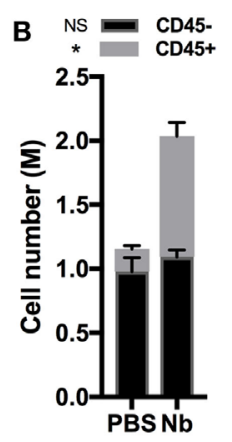
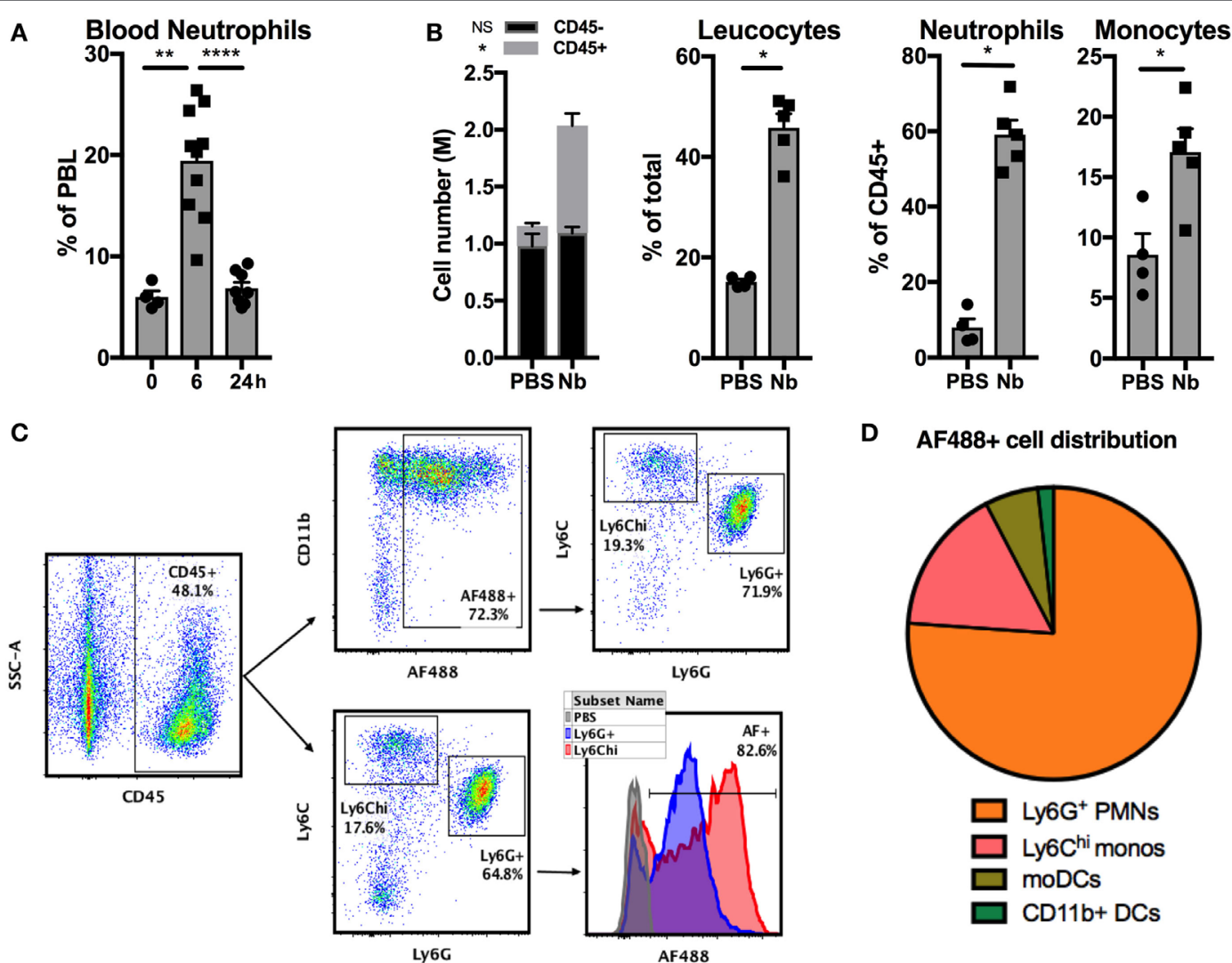

D AF488+ cell distribution

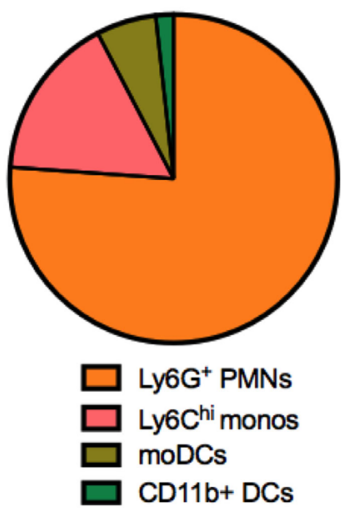

FIGURE 1 | Nippostrongylus brasiliensis (Nb) induces the recruitment and activation of neutrophils in the skin. C57BL/6 mice were injected intradermally into the ear with $600 \mathrm{AF} 488^{+} \mathrm{Nb}$ or PBS. The resulting inflammatory response in blood and skin was analyzed by flow cytometry at the indicated time points. Each symbol represents one mouse. (A) Proportion of neutrophils (CD11 $\left.\mathrm{b}^{\text {hi }} \mathrm{Ly} 6 \mathrm{G}^{+}\right)$in peripheral blood leukocytes (PBL). Data are pooled from two independent experiments. (B) Recruitment of leukocyte populations in the ear skin at $24 \mathrm{~h}$. Leukocytes were identified as CD $45^{+}$cells, neutrophils and monocytes were identified according to the gating in panel C. Data are from one of three experiments that gave similar results. (C) Representative dot plots depicting the gating of ear skin CD45+ populations expressing Ly6G (neutrophils), high Ly6C (monocytes), and AF488 as a measure of Nb uptake. (D) Pie chart showing the relative proportion of AF488 ${ }^{+}$ populations in skin, identified as in (C). Monocyte-derived DCs (moDCs) are defined as Ly6G- Ly6C $^{\text {hi }}$ CD11 $\mathrm{b}^{\text {hi }}$ CD11 $\mathrm{C}^{+} \mathrm{MHCll}^{+}$, and CD11 $\mathrm{b}^{+}$dendritic cells (DCs) are Ly6G- $\mathrm{Ly}_{6 \mathrm{C}}-\mathrm{CD} 11 \mathrm{C}^{+} \mathrm{MHCll}^{+} \mathrm{CD} 11 \mathrm{~b}^{+} \mathrm{CD}_{226}$. Data are from one of three experiments that gave similar results. Bar graphs show mean \pm SEM. Statistical analyses used the Mann-Whitney test. NS: not significant; ${ }^{\star} p<0.05 ;{ }^{* *} p<0.01$; ${ }^{* \star \star \star} p<0.0001$. (B) Symbols close to the legend indicate a comparison of the same population between the two groups. 
whole-mount confocal imaging of fixed ear dermis. An increased density of $\mathrm{DAPI}^{+}$cells close to the injected $\mathrm{Nb}$ was observed as early as $1 \mathrm{~h}$ post-injection (p.i.) (Figure 2A, left). Surprisingly, in addition to the cellular infiltrate, worms were also surrounded by large $\mathrm{DAPI}^{+}$fiber-shaped structures (Figure $2 \mathrm{~A}$, right). By $2 \mathrm{~h}$ after $\mathrm{Nb}$ injection, most of the cells associated with $\mathrm{Nb}$ were Ly6 $6 \mathrm{G}^{+}$neutrophils (Figure 2B, left). Interestingly, the Ly6G staining was often associated with the formation of extracellular $\mathrm{DAPI}^{+}$fiber-shaped structures, suggesting a neutrophil mediated phenomenon induced less than $1 \mathrm{~h}$ after $\mathrm{Nb}$ injection (Figure 2B, right).

Immunohistochemistry experiments to investigate the nature of the $\mathrm{DAPI}^{+}$structures surrounding $\mathrm{Nb}$ showed that extracellular DNA fibers were often co-localized in the extracellular space with the neutrophil granule enzymes neutrophil elastase (NE, Green) and myeloperoxidase (MPO, Red) (Figure 2C), commonly found in NETs. NET formation has been shown to be dependent on peptidyl arginine deiminase 4 activity and its histone $\mathrm{H} 3$ citrullination. Peptidyl arginine deiminase 4 facilitates nuclear DNA decondensation, and the release into the extracellular space of DNA coated by neutrophil granule enzymes and histones. Indeed, extracellular DNA fibers could be observed in the dermis for at least $48 \mathrm{~h}$ after $\mathrm{Nb}$ injection, and stained strongly for histone $\mathrm{H} 3$ citrullines thus identifying them as NETs (Figure 2D) (39-42).

\section{Nippostrongylus brasiliensis Induces an IFNAR1-Dependent and TLR4-Dependent Expression of BST2 on BM Cells}

We recently showed that the injection of non-viable $\mathrm{Nb}$ in the ear dermis induces a strong IFN-I transcriptional signature on the migratory DCs infiltrating the skin dLN, and that IFN-I signaling is important for an optimal Th2 immune response in this model (11). In order to study the $\mathrm{Nb}$ sensing mechanisms that lead to IFN-I secretion, we used primary BM cells as they contain high proportions of neutrophils and monocytes, which are the main cell types recruited to the ear dermis early after $\mathrm{Nb}$ injection. An analysis of the surface markers expressed by these cell populations showed that, compared to $\mathrm{AF} 488^{-/ \text {low }}$ cells, $\mathrm{AF} 488^{+}$ inflammatory monocytes, and to a lesser extent neutrophils, overexpressed the IFN-I-induced marker BST2 (11, 43) (Figure 3A). Treatment with IFNAR1-blocking antibodies reversed BST2 upregulation, confirming that it was dependent on IFNAR1 signaling (Figures 3B,C). Coculture with $\mathrm{SN}$ from $\mathrm{Nb}$ preparations, to determine if the IFN-I inducing factor present in $\mathrm{Nb}$ preparations sedimented with the $\mathrm{Nb}$ body or was a soluble factor, and coculture with house dust mite whole bodies (HDM) also induced an IFN-I-dependent upregulation of BST2 (Figure 3C). This latter observation is consistent with a very recent and elegant report showing that Schistosoma mansoni and HDM induce an IFN-I dependent Th2 response (12). Thus, several Th2 stimuli can induce the secretion of IFN-I by primary BM cells.

IFN-I is known to be produced in high amounts during antiviral and cellular immune responses, but much less is known about its secretion during metazoan parasite infections or other Th2 responses $(12,44)$. The mechanisms leading to the secretion of IFN-I have been mostly associated with the detection of viral nucleic acids or bacterial LPS (45-47). We used commercial tolllike receptor (TLR) reporter cell lines to investigate whether $\mathrm{Nb}$ preparations were able to trigger active signaling through these receptors. In vitro, non-viable $\mathrm{Nb}$ larvae induced the activation of NF- $\kappa \mathrm{B}$ only in reporter cell lines expressing TLR2 or TLR4, but not in those expressing TLR7 or TLR9, or their respective controls (Figure 3D). This suggests that Nb-induced IFN-I secretion is unlikely to be mediated by nucleic acid sensing, and that $\mathrm{Nb}$ can instead be detected by TLR2 and TLR4.

Coculture of non-viable $\mathrm{Nb}$ with fresh $\mathrm{BM}$ cells showed that $\mathrm{Nb}$ could induce an IFNAR1-dependent expression of BST2 on WT and TLR2 KO, but not TLR4 KO, BM monocytes (Figure 3E; Figure S1A in Supplementary Material), which is consistent with the reported differential capacity of these receptors to trigger IFN-I secretion (47). Anti-IFNAR1 antibody treatment decreased BST2 expression below control levels, suggesting a constitutive IFN-I signaling in BM cultures. Of note, IFNAR1 expression on monocytes was decreased upon $\mathrm{Nb}$ stimulation of WT and TLR2 KO BM, but was unaffected in the TLR4 KO BM cultures (Figure S1B in Supplementary Material). This is consistent with a ligand-induced endocytosis of IFNAR1, and an absence of IFN-I secretion only in the TLR4 KO background. Importantly, IFNAR1 expression and Nb-AF488 dye uptake were not influenced by TLR2 or TLR4 expression, revealing that these primary cells were not defective in IFN-I secretion, signaling, or phagocytosis in these conditions (Figure 3E; Figure S1C in Supplementary Material).

BST2 expression on monocytes and neutrophils was dosedependent and saturable after induction by $\mathrm{Nb}$ or by formalinfixed Gram-negative E. coli bacteria (data not shown). These experiments confirmed that the secretion of IFN-I induced by Gram-negative bacteria, known to be dependent on TLR4 signaling (47), could also be observed in BM cultures.

These results show that $\mathrm{Nb}$ preparations are able to signal through TLR2 and TLR4 in BM cells, and elicit the upregulation of BST2 expression via a TLR4-dependent and IFNAR1dependent pathway. However, the precise nature of these TLR4 ligands remains to be defined.

\section{TLR4 Mediates Nb-Induced Ifnb Expression, but Not NETosis, in the Skin}

We wished to assess the expression of IFN-I in the skin after $\mathrm{Nb}$ injection. Non-viable AF488 ${ }^{+} \mathrm{Nb}$ larvae induced expression of the IFN-I-induced marker BST2 on AF488 ${ }^{+}$monocytes, monocyte-derived DCs and CD $11 \mathrm{~b}^{+}$dermal DCs in the skin at $24 \mathrm{~h}$ p.i. (Figures 4 A,B), implying that IFN-I was secreted in the skin before $24 \mathrm{~h}$. The main components of the IFN-I family are transcribed from 14 Ifna, 1 Ifnb, 1 Ifnk, and 1 Ifne genes (48). Using RT-qPCR, we detected a transient expression of Ifnbl in ear skin, peaking at $2 \mathrm{~h}$ p.i. and disappearing quickly at later time points (Figure S2A in Supplementary Material). Other common IFN-I species including Ifna2 and Ifna4 were not detected in significant amounts during the first $6 \mathrm{~h}$ p.i. (data not shown). When $\mathrm{Nb}$-induced If $n$ expression was assessed in C57BL/6 and TLR4 $\mathrm{KO}$ mice, no Ifnb1 transcripts could be detected in TLR4 KO mice. Of note, we could also observe a trend toward a low expression 
A

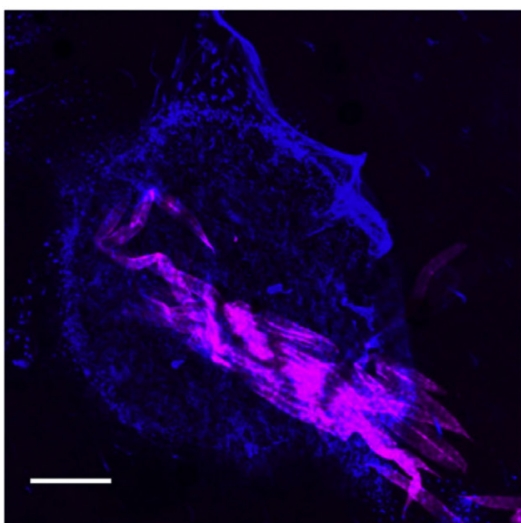

B

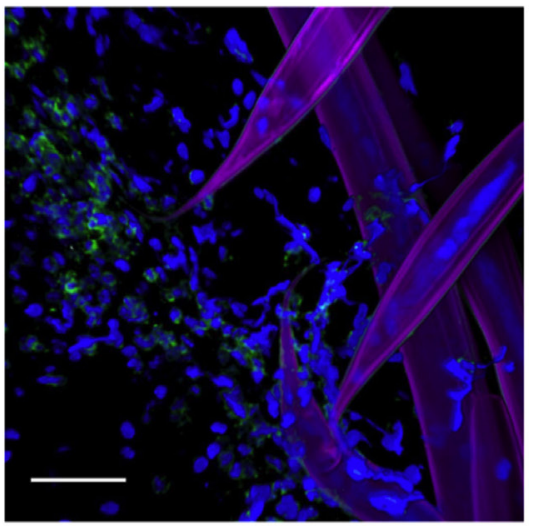

C
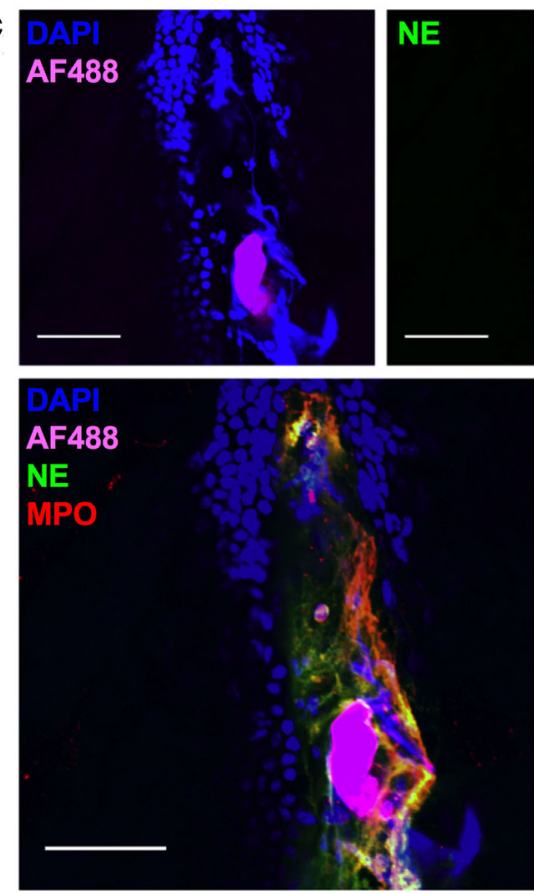
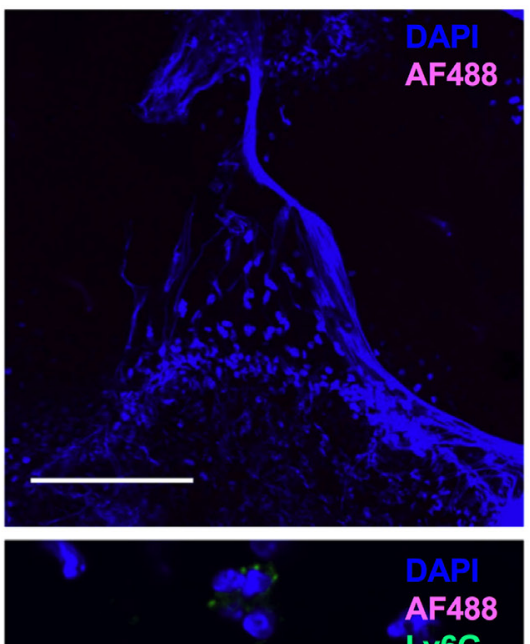

Ly6G
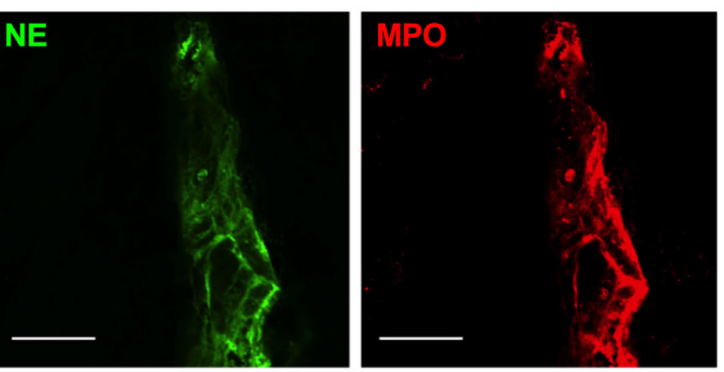

D

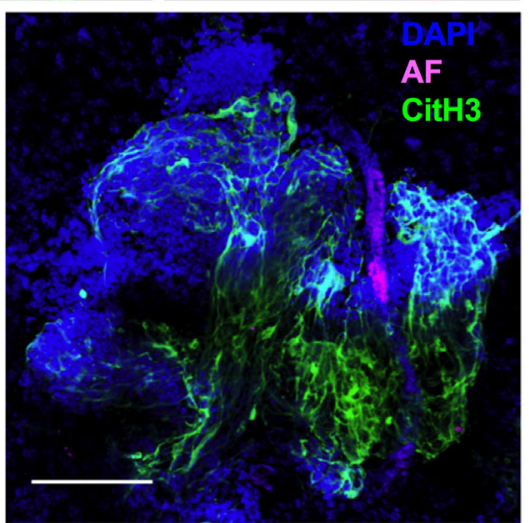

FIGURE 2 | Nippostrongylus brasiliensis (Nb) induces the formation of neutrophil extracellular traps in skin. C57BL/6 mice were injected intradermally into the ear with $150 \mathrm{AF} 488^{+} \mathrm{Nb}$, and z-stacks of whole-mount ear dermis were analyzed by immunofluorescence and confocal microscopy at different time points. Images are representative of at least two independent experiments. (A) Dermis at $1 \mathrm{~h}$ after AF488 ${ }^{+} \mathrm{Nb}$ injection showing $\mathrm{DAPl}^{+}$nuclei (blue) and $\mathrm{AF} 488^{+} \mathrm{Nb}(\mathrm{magenta})$. Bar $=200 \mu \mathrm{m}$. (B) Dermis at $2 \mathrm{~h}$ after AF488 ${ }^{+} \mathrm{Nb}$ injection showing DAPI+ nuclei (blue), AF488 ${ }^{+} \mathrm{Nb}$ (magenta), and Ly6G+ neutrophils (Green). Bar $=50 \mu \mathrm{m}$. (C) Dermis at $24 \mathrm{~h}$ after AF488+ Nb injection showing DAPI+ nuclei (blue), AF488+ Nb (magenta), myeloperoxidase (Red), and neutrophil elastase (Green). Bar $=50 \mu \mathrm{m}$. (D) Dermis at $48 \mathrm{~h}$ after AF488 ${ }^{+} \mathrm{Nb}$ injection showing DAPI ${ }^{+}$nuclei (blue), autofluorescent $\mathrm{Nb}$ (magenta), histone H3 citrullination (Green), and neutrophil elastase (Red). Bar $=200 \mu \mathrm{m}$. 


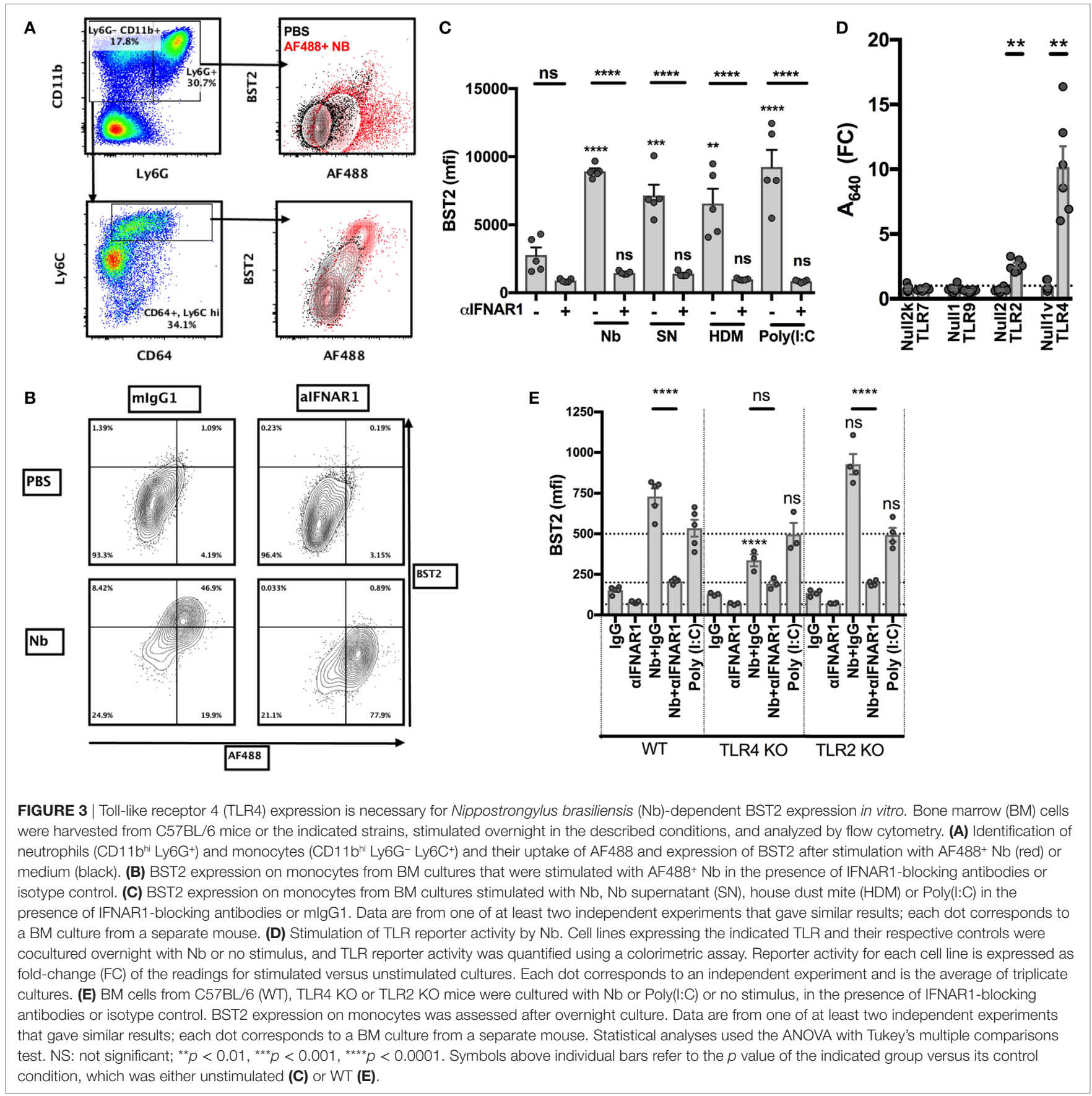

of Ifna (all species) (16) and Ifnk in C57BL/6 recipients, but again this was not observed in TLR4 KO mice (Figure 4C).

Plasmacytoid DCs are known to be the main producer of IFN-I on a per cell basis in antiviral responses and some autoimmune diseases. In these conditions, pDC IFN-I secretion is mainly induced by the detection of nucleic acids through TLR7 and TLR9, whereas the TLR4 pathway is not involved (49). We, therefore, used SiglecH-DTR mice to assess the contribution of pDCs to IFN-I production after $\mathrm{Nb}$ injection. Depletion of $\mathrm{pDCs}$ by i.p. treatment with DT had no effect on the expression of Ifnb1 in ear skin $2 \mathrm{~h}$ after $\mathrm{Nb}$ injection (Figure S2B in Supplementary
Material). Transcripts for Ifna or If $n k$, which could be detected at low levels in C57BL/6 mice, were undetectable in SiglecH-DTR mice on a Balb/c background (Figure S2B in Supplementary Material). These discrepancies might be explained by cell type and strain-specific differences in the expression of IFN-I family members (50). Together, these results suggest that $\mathrm{pDCs}$ are not involved in the IFN-I response to $\mathrm{Nb}$.

NETosis is known to be induced by various signaling pathways, including TLR2 and TLR4 activation $(51,52)$. As NETosis has been associated with the secretion of IFN-I by various cell types $(22-24,53)$, we investigated whether $\mathrm{Nb}$-induced NETosis 


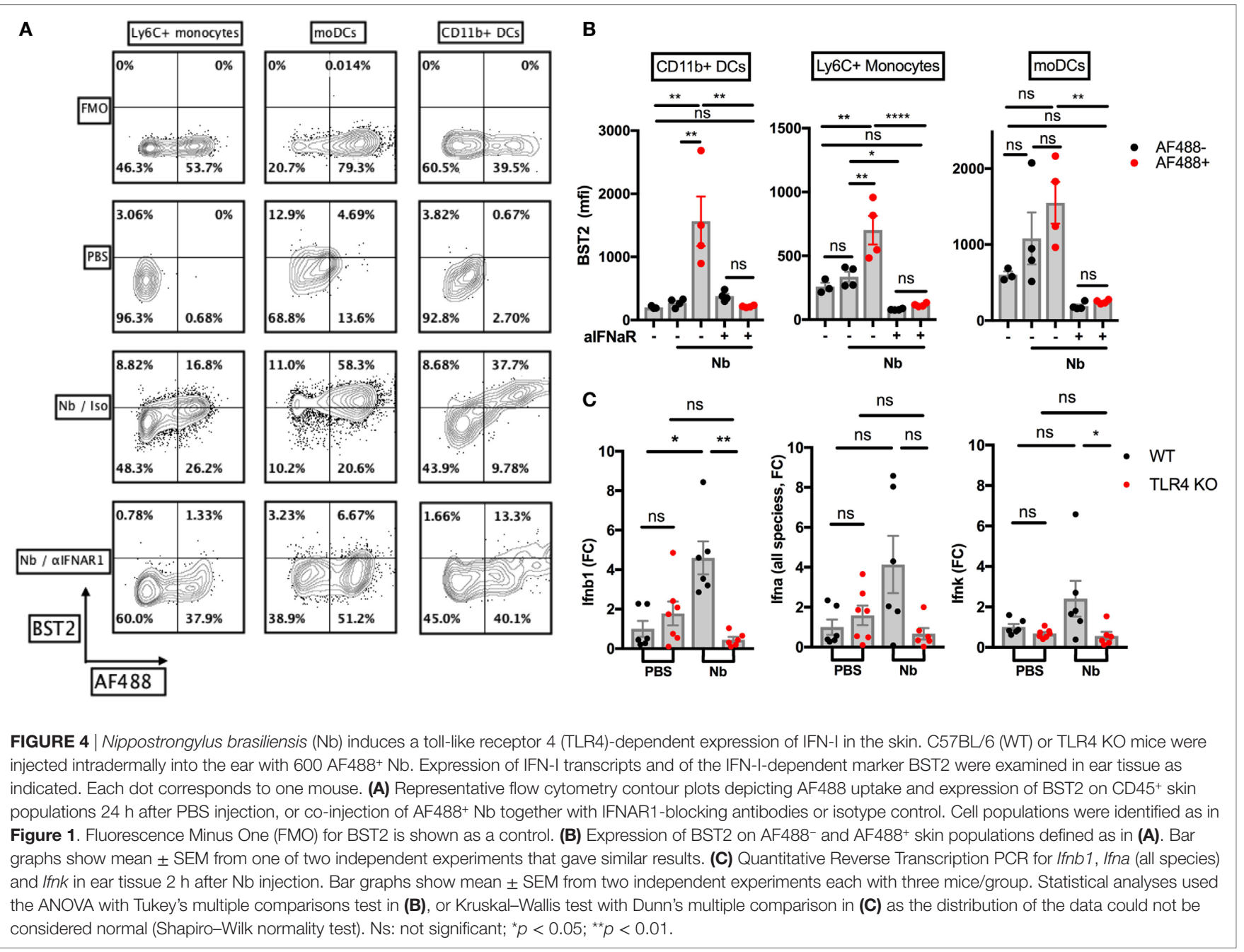

required the expression of TLR2 or TLR4. We were able to observe NETosis in the skin of mutant mice as early as $1 \mathrm{~h}$ after non-viable $\mathrm{Nb}$ injection, ruling out a key requirement for either TLR2 or TLR4 in mediating Nb-induced NETosis (Figure S3 in Supplementary Material).

\section{Expression of an IFN-I signature on migratory DC requires host TLR4 expression but not NET formation}

Injection of $\mathrm{AF} 488^{+} \mathrm{Nb}$ is followed by the migration of $\mathrm{AF} 488^{+}$ skin DCs from the skin to the dLN. AF $488^{+}$DCs in dLN peak in number at day 2 p.i. and mostly comprise the $\mathrm{CD}_{11 \mathrm{~b}^{+} \text {and }}$ CD $326^{-} \mathrm{CD}_{103}{ }^{-} \mathrm{CD} 11 \mathrm{~b}^{-}$, or Triple negative (TN), DC subsets. Work from our group has shown that these two subsets of migratory DCs express an IFN-I signature that can be revealed by their expression of BST2 (11). We compared expression of BST2 on $\mathrm{CD} 1 \mathrm{bb}^{+}$and TN DCs from WT or TLR4 KO mice, and found that, despite comparable AF488 uptake, BST2 was not upregulated in AF488 ${ }^{+}$DCs from TLR4 KO mice (Figure 5A). This observation is consistent with the lack of detectable IFN-I transcripts in TLR4 KO mice (Figure 4C).
Infection with live $\mathrm{Nb}$ also involves exposure to the microorganisms naturally associated with these helminths. Indeed $\mathrm{Gr} 1^{+}$ cells (including, but not limited to, neutrophils, inflammatory monocytes, and pDCs), have been shown to be determinant in controlling bacterial proliferation and the survival of mice infected with $\mathrm{Nb}$, thereby enabling the development of a canonical Th2 response instead of a Th1 response (27).

We investigated whether contamination by Gram-negative fecal bacteria was triggering the IFN-I response to Nb. Antibioticsterilized $\mathrm{Nb}$ preparations ( $\mathrm{sNb}$ ) (27) induced similar expression of BST2 and of the maturation marker CD86 on $\mathrm{AF} 488^{+} \mathrm{CD} 11 \mathrm{~b}^{+}$ and TN DCs infiltrating the ear $\mathrm{dLN}$ at day 2 p.i. (Figure S4A in Supplementary Material).

Injecting limiting numbers of an $\mathrm{Nb}$ preparation that had been extensively washed to lower endotoxin content (LE-Nb, $<5 \mathrm{EU} / \mathrm{mL}$ versus $\mathrm{Nb},>40 \mathrm{EU} / \mathrm{mL}$ ) still induced significant BST2 upregulation on $\mathrm{AF} 488^{+} \mathrm{DCs}$ in dLN (Figure 5B). Co-injection of 10,000 E. coli together with LE-Nb enhanced the IFN-I signature of AF $488^{+}$DCs (Figure 5B). These results show that TLR4 ligands from helminths and/or their associated microorganisms allow the development of an IFN-I signature on migratory DCs in skin dLN. 

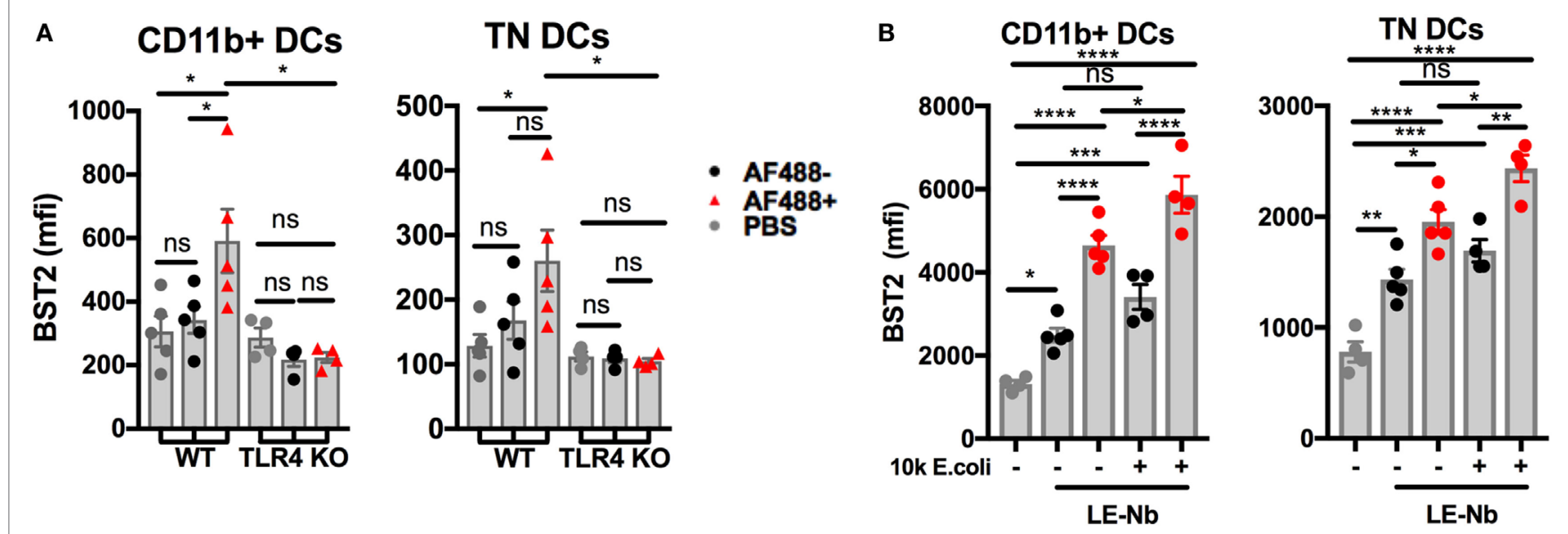

C

AF488-

AF488+

TN DCs
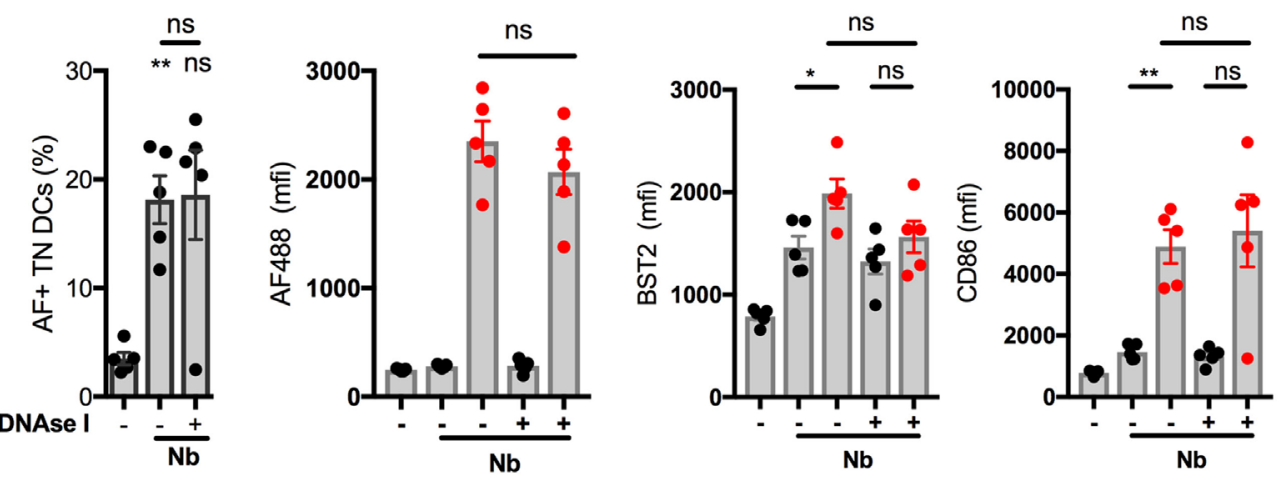

CD11b+ DCs
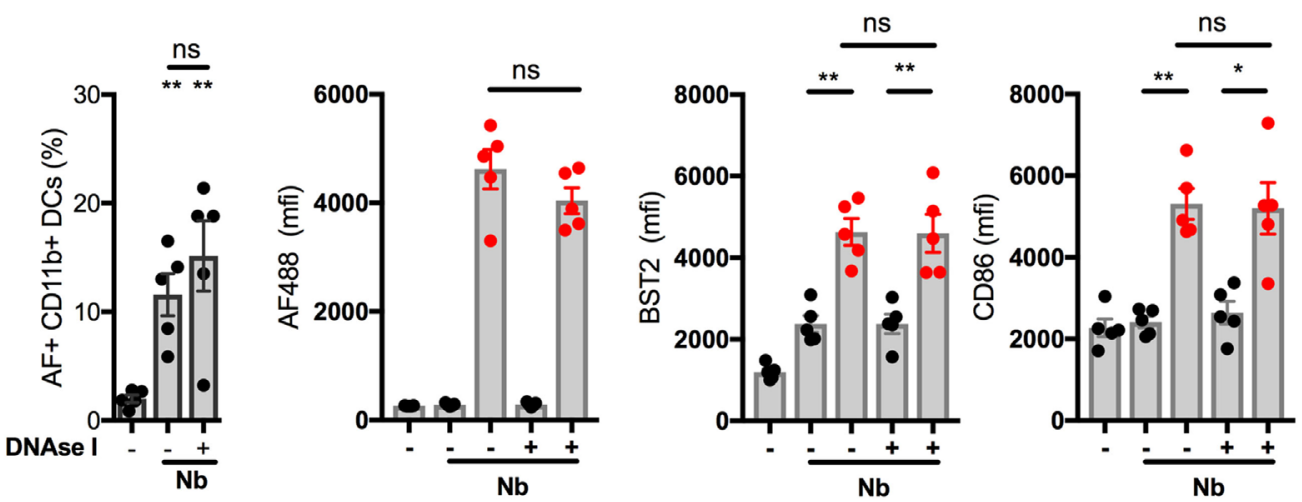

FIGURE 5 | Toll-like receptor 4 (TLR4), not extracellular DNA, drives the development of an IFN-I signature on LN dendritic cells (DCs) after Nippostrongylus brasiliensis (Nb) injection. C57BL/6 or TLR4 KO mice were injected intradermally into the ear with AF488+ $\mathrm{Nb}$. Uptake of AF488 and expression of CD86 and the IFN-I-dependent marker BST2 were examined in ear draining lymph node (dLN) DCs by flow cytometry $48 \mathrm{~h}$ after Nb injection. CD11 b+ DCs were CD11 $\mathrm{c}^{+} \mathrm{MHCl|}{ }^{\mathrm{hi}}$

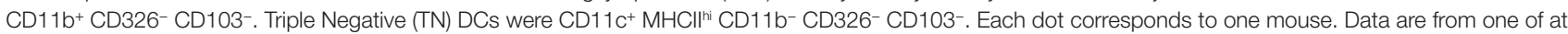
least two repeat experiments that gave similar results. (A) AF488 uptake and BST2 expression on subsets of migratory DCs in dLN of C57BL/6 (WT) or TLR4 KO mice after injection of 600 AF488+ Nb. (B) BST2 expression on subsets of migratory DCs in the dLN of C57BL/6 mice after co-injection of 300 Low-Endotoxin (LE, $<5$ Endotoxin Units $/ \mathrm{mL}$ ) AF488 ${ }^{+} \mathrm{Nb}$ with or without 10,000 formalin-fixed E coli. (C) AF488 uptake and BST2 or CD86 expression on subsets of migratory DCs in the dLN of C57BL/6 mice after injection of $600 \mathrm{AF} 488^{+} \mathrm{Nb}$ with or without DNase I treatment. Bar graphs show mean \pm SEM. Statistical analyses used the ANOVA with Tukey's multiple comparisons test. Ns: not significant; ${ }^{*} p<0.05 ;{ }^{* \star} p<0.01 ;{ }^{\star \star \star} p<0.001$.

As $\mathrm{Nb}$ injection induced NETosis and IFN-I secretion, we investigated whether NETs could mediate Nb-induced IFN-I expression. Regular administrations of high doses of DNase I are reported to digest NETs in vivo (33). Here, i.d. injection of 2,000 U DNase I together with $\mathrm{Nb}$ inhibited the formation of
NETs at 2 h p.i., as assessed by microscopy (data not shown). However, regular injections of DNase I (i.d. and then i.p. every $12 \mathrm{~h}$ ) was unable to reduce BST2 expression on AF488 ${ }^{+} \mathrm{DCs}$ in dLN at $24 \mathrm{~h}$ and $48 \mathrm{~h}$ after $\mathrm{Nb}$ injection (Figure $5 \mathrm{C}$ and data not shown). Neutrophil depletion using anti-Ly6G or anti-Gr1 
antibody treatment was also unable to prevent $\mathrm{Nb}$-induced BST2 expression on AF488 ${ }^{+}$DCs in dLN (Figure S5A,B in Supplementary Material). These results show that the IFN-I signature on dLN DCs from $\mathrm{Nb}$-injected mice was not uniquely dependent on neutrophils or extracellular DNA.

Together, these data suggest that $\mathrm{Nb}$ and its associated TLR4 ligands induce the expression of IFN-I in the skin (7, 54-56), and an IFN-I signature on antigen-bearing migratory DCs in the dLN (11).

\section{TLR4 Signaling Enhances the Development of Th2 Responses to $\mathrm{Nb}$}

As shown in Figure 5, TLR4 signaling is necessary for $\mathrm{Nb}$-induced BST2 expression on AF488 ${ }^{+}$DCs in dLN. We have previously shown that $\mathrm{Th} 2$ immune responses to $\mathrm{Nb}$ are reduced by blocking IFN-I signaling (11). We, therefore, assessed the ability of $\mathrm{Nb}$ preparations with different endotoxin content to induce $\mathrm{T}$ cell responses. As shown in Figure 6A, reducing the endotoxin content of $\mathrm{Nb}$ preparations decreased $\mathrm{dLN}$ cellularity and IL4 $4^{+}$ and IFN $\gamma^{+} \mathrm{T}$ cell responses. Adding 10,000 E. coli to "LowEndotoxin" $\mathrm{Nb}$ preparations was able to rescue the percentages and numbers of both $\mathrm{IL} 4^{+}$and IFN $\gamma^{+} \mathrm{CD} 4^{+} \mathrm{T}$ cells (Figure 6A).

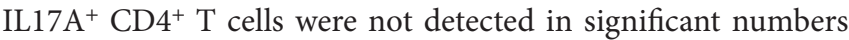
after $\mathrm{Nb}$ injection thus the effect of TLR4 signaling could not be assessed in this population.

We then assessed the impact of TLR4 deficiency on the contribution of IFN-I signaling to the T cell response. As shown in Figure 6B, TLR4 KO mice showed lower dLN cellularity and lower cytokine responses to $\mathrm{Nb}$ injection. In addition, treatment with IFNAR1-blocking antibodies was unable to decrease IL4 ${ }^{+} \mathrm{T}$ cell responses in TLR4 KO hosts, which is consistent with the lack of IFN-I production in these mice. A similar effect was seen also on $\mathrm{IL}_{10}{ }^{+} \mathrm{CD} 4^{+} \mathrm{T}$ cells. IFN $\gamma^{+} \mathrm{CD} 4^{+} \mathrm{T}$ cell responses were essentially ablated by blocking IFN-I signaling and by TLR4 deficiency. Of note, a small population of IL4 ${ }^{+} \mathrm{IL}_{10} 0^{+} \mathrm{CD} 4^{+} \mathrm{T}$ cells was induced
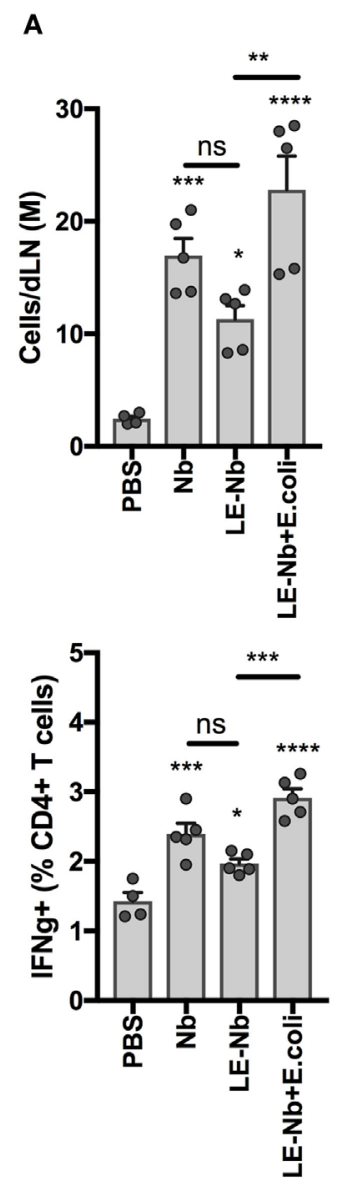

B
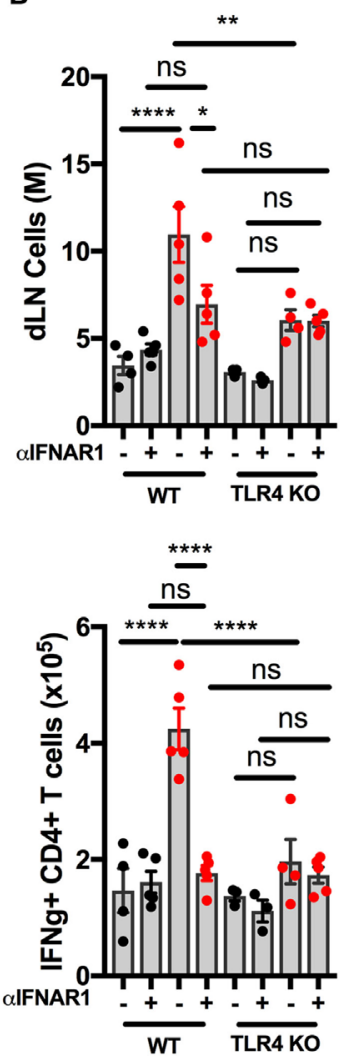
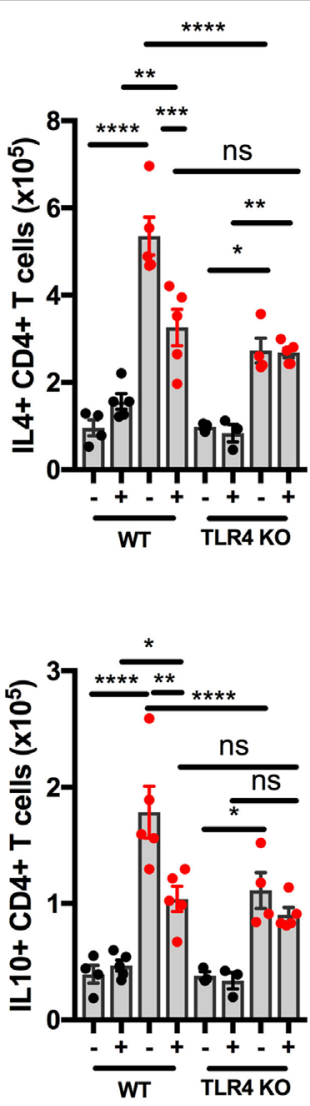

FIGURE 6 | Toll-like receptor 4 (TLR4) enhances the development of CD4+IL4+ T cells after Nippostrongy/us brasiliensis (Nb) injection. C57BL/6 or TLR4 KO mice were injected intradermally into the ear with $150 \mathrm{Nb}$ from different preparations. T cell responses were measured in the draining lymph node by intracellular cytokine staining and flow cytometry 7 days after $\mathrm{Nb}$ injection. Each dot corresponds to one mouse. Data are from one of at least two repeat experiments that gave similar results. (A) T cell cytokine response in C57BL/6 mice injected with Nb, or Low Endotoxin (LE, <5 Endotoxin U/mL) Nb, or Low Endotoxin Nb preparations (LE-Nb) plus 10,000 formalin-fixed E coli. (B) T cell cytokine response in C57BL/6 (WT) and TLR4 KO mice injected with Nb together with IFNAR1-blocking antibodies or isotype control. Bar graphs show mean \pm SEM. Statistical analyses used the ANOVA with Tukey's multiple comparisons test. Ns: not significant; ${ }^{*} p<0.05$; ${ }^{\star \star} p<0.01 ;{ }^{* \star *} p<0.001 ;{ }^{\star \star \star *} p<0.0001$. 
after $\mathrm{Nb}$ immunization, but was independent of IFN-I signaling or TLR4 expression $\left(13.47 \pm 2.47 \%\right.$ of $\mathrm{IL}^{+}{ }^{+} \mathrm{CD} 4^{+} \mathrm{T}$ cells, data not shown).

These results show that TLR4 ligands can amplify Nb-induced $\mathrm{T}$ cell responses through an IFN-I-dependent mechanism. The role of TLR4 and IFN-I signaling appears to be in enhancing the magnitude of the $\mathrm{T}$ cell immune response to $\mathrm{Nb}$, rather than specifically skewing the response toward Th2.

\section{DISCUSSION}

In this paper, we show that the detection of $\mathrm{Nb}$ and/or its associated microorganisms through TLR4 allows a transient secretion of IFN-I in the skin. Preventing TLR4 signaling ablated the upregulation of IFN-I-induced markers on DCs and dampened the development of IFN $\gamma$, IL10, and IL4-secreting T cells, suggesting that TLR4 and IFNAR signaling are important but non-specific amplifiers of adaptive immune responses to $\mathrm{Nb}$. We also show that $\mathrm{Nb}$ induces a potent recruitment and activation of neutrophils in the dermis and the formation of NETs. However, we were unable to demonstrate an effect of neutrophils or NETs on the number of $\mathrm{Nb}^{+} \mathrm{DCs}$ in $\mathrm{dLN}$, or on their expression of the IFN-I-induced marker BST2 and the activation marker CD86, suggesting that NET formation does not drive immune activation in response to $\mathrm{Nb}$.

Neutrophils are the main cell type recruited early to the site of non-viable $\mathrm{Nb}$ injection. We show that neutrophils interact with $\mathrm{AF} 488^{+} \mathrm{Nb}$ in the skin, taking up a substantial quantity of the fluorescent dyes associated with it (Figure 1). NETs have been associated with the secretion of IFN-I in different models, and have been recently implicated in mediating the exacerbation of an asthmatic Th2 response induced by rhinovirus infection $(23,24,34,53)$. Unexpectedly, we could not find any impact of neutrophil depletion or NET digestion on the development of the IFN-I signature on antigen-bearing dLN DCs in our model. Indeed, $\mathrm{Gr}^{+}$cells, including neutrophils, have not been reported to contribute to the development of primary adaptive immune responses to sterile preparations of live $\mathrm{Nb}$ (27). However, neutrophils have been shown to improve memory protective responses to $\mathrm{Nb}$ through their control of alternative activation of macrophages in the lung (28). As NETosis is preferentially induced by the sensing of large pathogens (39), it could represent a mechanism of helminth trapping and killing (57). As antibodies and complement are important for neutrophil activation during NETosis (40), it appears to be worthwhile investigating whether the NETosis process contributes to antihelminthic protective immunity during secondary responses.

We show that endotoxins or endotoxin-containing bacteria, which are both commonly present in the helminth natural environment, can increase the Th2 response to $\mathrm{Nb}$ by inducing a quick and transient expression of IFN-I in the skin. Antibiotic sterilization of $\mathrm{Nb}$ preparations did not affect BST2 expression on $\mathrm{AF} 488^{+} \mathrm{DCs}$ in dLN, revealing that bacterial proliferation or secretions in vivo were not important for this mechanism (Figure S4A in Supplementary Material). Adding extra washing steps during $\mathrm{Nb}$ preparation to diminish their potential endotoxin content was sufficient to decrease the development of an IFN-I signature on $\mathrm{AF} 488^{+} \mathrm{dLN}$ DCs and the Th2 response to the worms. These effects could be reversed by the addition of a small number of $E$. coli at the time of Nb injection. In addition, the $\mathrm{SN}$ from $\mathrm{Nb}$ preparations could enhance the IFN-I signature on primary $\mathrm{BM}$ cells as much as $\mathrm{Nb}$ themselves (Figure 3C). Therefore, Gram-negative bacteria or endotoxins have a potential role in shaping DC activation after helminth injection, and the development of antihelminthic Th2 responses (Figures 5B and $6 \mathrm{~A}$ ). In this regard, it is nonetheless important to note that our efforts to completely eliminate the TLR4-dependent activity from $\mathrm{Nb}$ preparations were overall unsuccessful, suggesting the possibility that selected $\mathrm{Nb}$ components may be able to directly engage TLR4 and initiate signaling as was described for HDM DerP1 (58). Indeed, various helminths are reported to express glycans, glycolipids, or proteinases whose products are able to activate $\operatorname{TLR} 4(7,54,56,59)$.

We previously showed that TLR4 deficiency had no effect on theinduction of Th2 responses to Nb in IL4-reporter G4 mice(29). The Th2 immune response to $\mathrm{Nb}$ is dose-dependent, and using a "saturating" dose of $\mathrm{Nb}$, such as $600 \mathrm{~L} 3$ larvae, prevented us from observing significant differences at that time. In this context, if the development of a Th2 immune response is the result of the integration of diverse redundant signals, one might not observe the contribution of each of these signals if the system is saturated by an optimal dose of stimulus. Indeed, IL25, IL33, and TSLP can each contribute redundantly to the optimal Th2 immune response in various organs and contexts, possibly compensating for the effects of TLR4-dependent IFN-I secretion (5). Here, we were able to observe a TLR4 dependency on the development of a Th2 immune response to a suboptimal dose of $\mathrm{Nb}$ (Figure 6B).

Our data suggest that TLR4, which is not expressed on conventional $\mathrm{DC}$, enables the sensing of $\mathrm{Nb}$ and its associated microorganisms as a danger signal to induce IFN-I expression and indirectly enhance DC activation, maturation, and/or functional abilities $(16,60-62)$. The secretion of IFN-I induced by $\mathrm{Nb}$ was completely abrogated in TLR4 KO mice. As a result, we could not observe any effect of IFNAR blockade on the Th2 response to $\mathrm{Nb}$ in TLR4 KO mice. More importantly, TLR4 and its coreceptor CD14 are known to be mainly expressed by monocyte and macrophage populations. As neutrophils and monocytes were found to be the main cell types interacting with $\mathrm{Nb}$ early in the skin, and as neutrophils were not found to be critical in mediating $\mathrm{Nb}$-induced IFN-I secretion, we can speculate that $\mathrm{Nb}$ sensing by monocyte and/or macrophage populations is involved in this process. Indeed, LPS recognition through TLR4 expression by macrophages is a well-known stimulus of TRIF-dependent If $n b$ expression (47). However, we cannot exclude the possibility that other cells such as keratinocytes (63), or TLR4-mediated IFN-I independent effects, might also contribute to the development of Th2 responses. Indeed, in HDM-mediated asthma models, TLR4 expression by airway epithelial cells has been shown to contribute in a MyD88-dependent but TRIF-independent fashion to the development of an IL1-, alarmin-, and GM-CSF-mediated DC activation to allow the development of a pathogenic $\mathrm{Th} 2$ response (64-66). Interestingly, the expression of IRF3 by DCs was found to be critical for their optimal maturation, and for the development of asthma in similar models. However, no role was found for TRIF or IFN-I signaling through IFNAR2 blockade in those 
studies (67). Very recently, Webb et al reported that IFN-I signaling was indeed important for DC activation, maturation, and their induction of Th2 responses by both HDM and Schistosoma mansoni (12). As HDM and S. mansoni are both known to activate TLR4, the TLR4-IFN-I axis might be an important mechanism enhancing DC maturation and Th2 responses in various pathologies, from helminthiases to allergic diseases.

The life cycle of many parasitic helminths involves several distinct phases where helminths feed on bacteria during their free-living phase in the soil, and then spend most of their parasitic phase in the gut while infecting their host. It is difficult to conceive how a natural helminth infection could take place without involving barrier disruption of the host and a small-scale invasion by its surrounding microorganisms. Gram-negative bacteria such as Wolbachia can be associated with helminths, including most human-infecting filarial nematodes, in symbiotic (or obligatory symbiotic) relationships. Wolbachia-derived endotoxins have been shown to strongly affect the inflammatory response to Brugia malayi nematodes through TLR4 (68). Our results here suggest that, if DCs integrate signals from helminths and from epithelial barrier disruption to shape a Th2 immune response, the detection of the endotoxins originating from helminthassociated microflora could also participate via a TLR4 and IFN-I-dependent mechanism.

Our work strongly suggests that, if a limited activation of antibacterial signaling pathways is likely to occur in a natural helminth infection, it might contribute to, and not inhibit, the development of antihelminthic Th2 responses.

\section{ETHICS STATEMENT}

All experimental protocols were approved by the Victoria University of Wellington Animal Ethics Committee (Permit 2014R17M) and performed according to Institutional guidelines.

\section{REFERENCES}

1. Walsh KP, Mills KHG. Dendritic cells and other innate determinants of T helper cell polarisation. Trends Immunol (2013) 34:521-30. doi:10.1016/j. it.2013.07.006

2. Fitzsimmons CM, Falcone FH, Dunne DW. Helminth allergens, parasitespecific IgE, and its protective role in human immunity. Front Immunol (2014) 5:61. doi:10.3389/fimmu.2014.00061

3. Palm NW, Rosenstein RK, Medzhitov R. Allergic host defences. Nature (2012) 484:465-72. doi:10.1038/nature11047

4. Méndez-Samperio P. Molecular events by which dendritic cells promote Th2 immune protection in helmith infection. Infect Dis (Auckl) (2016) 4235:1-6. doi:10.1080/23744235.2016.1194529

5. Vannella KM, Ramalingam TR, Borthwick LA, Barron L, Hart KM, Thompson RW, et al. Combinatorial targeting of TSLP, IL-25, and IL-33 in type 2 cytokine - driven inflammation and fibrosis. Sci Transl Med (2016) 8:1-13. doi:10.1126/scitranslmed.aaf1938

6. Eisenbarth SC, Piggott DA, Huleatt JW, Visintin I, Herrick CA, Bottomly K. Lipopolysaccharide-enhanced, toll-like receptor 4-dependent $\mathrm{T}$ helper cell type 2 responses to inhaled antigen. J Exp Med (2002) 196:1645-51. doi:10.1084/jem.20021340

7. Thomas PG, Carter MR, Atochina O, Da'Dara AA, Piskorska D, McGuire E, et al. Maturation of dendritic cell 2 phenotype by a helminth glycan uses a

\section{AUTHOR CONTRIBUTIONS}

$\mathrm{CP}$ carried out experiments, analyzed the data and wrote the manuscript. S-CT generated $\mathrm{Nb}$ stocks and carried out experiments. AS and JD designed, optimized, and analyzed confocal microscopy experiments. RW and OL carried out RT-qPCR time courses. CR provided essential reagents and experimental advice. LC provided conceptual insights and data on the model. GLG and FR provided conceptual insights and FR supervised the project. All Authors provided feedback on the manuscript.

\section{ACKNOWLEDGMENTS}

The authors wish to thank the expert support of the Malaghan Institute of Medical Research Hugh Green Cytometry Core, Research Information Technologies and Biomedical Research Unit staff. We are extremely grateful to Professor Shizuo Akira, Osaka University, for donating TLR2 KO and TLR4 KO mice.

\section{FUNDING}

This research was funded by an Independent Research Organizations grant from the Health Research Council of New Zealand to the MIMR, and in part by a Polish National Center for Science grant 2013/11/B/NZ3/00189 to JD. This work was made possible by the gracious gift of a FV1200 confocal microscope by the Infinity Foundation, New Zealand.

\section{SUPPLEMENTARY MATERIAL}

The Supplementary Material for this article can be found online at http://www.frontiersin.org/article/10.3389/fimmu.2017.01575/ full\#supplementary-material. toll-like receptor 4-dependent mechanism. J Immunol (2003) 171:5837-41. doi:10.4049/jimmunol.171.11.5837

8. Pullan RL, Smith JL, Jasrasaria R, Brooker SJ. Global numbers of infection and disease burden of soil transmitted helminth infections in 2010. Parasit Vectors (2014) 7:37. doi:10.1186/1756-3305-7-37

9. Wills-Karp M, Santeliz J, Karp CL. The germless theory of allergic disease: revisiting the hygiene hypothesis. Nat Rev Immunol (2001) 1:69-75. doi: $10.1038 / 35095579$

10. The World Allergy Organisation. In: Pawankar R, Canonica GW, Holgate ST, Lockey RF, Blaiss MS. The White Book on Allergy: Update 2013. The World Allergy Organization Journal. (2014). $7 \mathrm{p}$.

11. Connor LM, Tang SC, Cognard E, Ochiai S, Hilligan KL, Old SI, et al. Th2 responses are primed by skin dendritic cells with distinct transcriptional profiles. J Exp Med (2017) 214:125-42. doi:10.1084/jem.20160470

12. Webb LM, Lundie RJ, Borger JG, Brown SL, Connor LM, Cartwright AN, et al. Type I interferon is required for T helper (Th) 2 induction by dendritic cells. EMBO J (2017) 36(16):2404-18. doi:10.15252/embj.201695345

13. Le Bon A, Tough DF. Type I interferon as a stimulus for cross-priming. Cytokine Growth Factor Rev (2008) 19:33-40. doi:10.1016/j.cytogfr.2007.10.007

14. Ivashkiv LB, Donlin LT. Regulation of type I interferon responses. Nat Rev Immunol (2014) 14:36-49. doi:10.1038/nri3581

15. Crouse J, Kalinke U, Oxenius A. Regulation of antiviral T cell responses by type I interferons. Nat Rev Immunol (2015) 15:231-42. doi:10.1038/nri3806 
16. Gautier G, Humbert M, Deauvieau F, Scuiller M, Hiscott J, Bates EE, et al. A type I interferon autocrine-paracrine loop is involved in Toll-like receptor-induced interleukin-12p70 secretion by dendritic cells. J Exp Med (2005) 201:1435-46. doi:10.1084/jem.20041964

17. Simmons DP, Wearsch PA, Canaday DH, Meyerson HJ, Liu YC, Wang Y, et al. Type I IFN drives a distinctive dendritic cell maturation phenotype that allows continued class II MHC synthesis and antigen processing. J Immunol (2012) 188:3116-26. doi:10.4049/jimmunol.1101313

18. Pantel A, Teixeira A, Haddad E, Wood EG, Steinman RM, Longhi MP. Direct type I IFN but not MDA5/TLR3 activation of dendritic cells is required for maturation and metabolic shift to glycolysis after poly IC stimulation. PLoS Biol (2014) 12(1):e1001759. doi:10.1371/journal.pbio.1001759

19. Nagai T, Devergne O, Mueller TF, Perkins DL, van Seventer JM, van Seventer GA. Timing of IFN- exposure during human dendritic cell maturation and naive Th cell stimulation has contrasting effects on Th1 subset generation: a role for IFN-mediated regulation of IL-12 family cytokines and IL-18 in naive Th cell differentiation. J Immunol (2003) 171:5233-43. doi:10.4049/ jimmunol.171.10.5233

20. Honda K, Sakaguchi S, Nakajima C, Watanabe A, Yanai H, Matsumoto M, et al. Selective contribution of IFN-alpha/beta signaling to the maturation of dendritic cells induced by double-stranded RNA or viral infection. Proc Natl Acad Sci U S A (2003) 100:10872-7. doi:10.1073/pnas.1934678100

21. Kaisho T, Hoshino K, Iwabe T, Takeuchi O, Yasui T, Akira S. Endotoxin can induce MyD88-deficient dendritic cells to support $\mathrm{T}(\mathrm{h}) 2$ cell differentiation. Int Immunol (2002) 14:695-700. doi:10.1093/intimm/dxf039

22. Gehrke N, Mertens C, Zillinger T, Wenzel J, Bald T, Zahn S, et al. Oxidative damage of DNA confers resistance to cytosolic nuclease TREX1 degradation and potentiates STING-dependent immune sensing. Immunity (2013) 39:482-95. doi:10.1016/j.immuni.2013.08.004

23. Lood C, Blanco LP, Purmalek MM, Carmona-Rivera C, De Ravin SS, Smith CK, et al. Neutrophil extracellular traps enriched in oxidized mitochondrial DNA are interferogenic and contribute to lupus-like disease. Nat Med (2016) 22:146-53. doi:10.1038/nm.4027

24. Garcia-Romo GS, Caielli S, Vega B, Connolly J, Allantaz F, Xu Z, et al. Netting neutrophils are major inducers of type I IFN production in pediatric systemic lupus erythematosus. Sci Transl Med (2011) 3:73ra20. doi:10.1126/ scitranslmed.3001201

25. Marichal T, Ohata K, Bedoret D, Mesnil C, Sabatel C, Kobiyama K, et al. DNA released from dying host cells mediates aluminum adjuvant activity. Nat Med (2011) 17:996-1002. doi:10.1038/nm.2403

26. Bouchery T, Kyle R, Camberis M, Shepherd A, Filbey K, Smith A, et al. ILC2s and $\mathrm{T}$ cells cooperate to ensure maintenance of M2 macrophages for lung immunity against hookworms. Nat Commun (2015) 6:6970. doi:10.1038/ ncomms7970

27. Pesce JT, Liu Z, Hamed H, Alem F, Whitmire J, Lin H, et al. Neutrophils clear bacteria associated with parasitic nematodes augmenting the development of an effective Th2-type response. J Immunol (2008) 180:464-74. doi:10.4049/ jimmunol.180.1.464

28. Chen F, Wu W, Millman A, Craft JF, Chen E, Patel N, et al. Neutrophils prime a long-lived effector macrophage phenotype that mediates accelerated helminth expulsion. Nat Immunol (2014) 15:938-46. doi:10.1038/ni.2984

29. Camberis M, Prout M, Tang SC, Forbes-Blom E, Robinson M, Kyle R, et al. Evaluating the in vivo Th2 priming potential among common allergens. J Immunol Methods (2013) 394:62-72. doi:10.1016/j.jim.2013.05.004

30. Okano M, Satoskar AR, Nishizaki K, Harn DA Jr, Lacto-N-fucopentaose III found on Schistosoma mansoni egg antigens functions as adjuvant for proteins by inducing Th2-type response. J Immunol (2001) 167:442-50. doi:10.4049/ jimmunol.167.1.442

31. Swiecki M, Wang Y, Riboldi E, Kim AH, Dzutsev A, Gilfillan S, et al. Cell depletion in mice that express diphtheria toxin receptor under the control of SiglecH encompasses more than plasmacytoid dendritic cells. J Immunol (2014) 192:4409-16. doi:10.4049/jimmunol.1303135

32. Takeuchi O, Hoshino K, Kawai T, Sanjo H, Takada H, Ogawa T, et al. Differential roles of TLR2 and TLR4 in recognition of gram-negative and gram-positive bacterial cell wall components. Immunity (1999) 11:443-51. doi:10.1016/S1074-7613(00)80119-3

33. Wong SL, Demers M, Martinod K, Gallant M, Wang Y, Goldfine AB, et al. Diabetes primes neutrophils to undergo NETosis, which impairs wound healing. Nat Med (2015) 21:815-9. doi:10.1038/nm.3887
34. Toussaint M, Jackson DJ, Swieboda D, Guedán A, Tsourouktsoglou TD, Ching YM, et al. Host DNA released by NETosis promotes rhinovirus-induced type-2 allergic asthma exacerbation. Nat Med (2017) 23(6):681-91. doi:10.1038/nm.4332

35. Charles N, Hardwick D, Daugas E, Illei GG, Rivera J. Basophils and the T helper 2 environment can promote the development of lupus nephritis. Nat Med (2010) 16:701-7. doi:10.1038/nm.2159

36. Schindelin J, Arganda-Carreras I, Frise E, Kaynig V, Longair M, Pietzsch T, et al. Fiji: an open-source platform for biological-image analysis. Nat Methods (2012) 9:676-82. doi:10.1038/nmeth.2019

37. Schmid B, Schindelin J, Cardona A, Longair M, Heisenberg M. A high-level 3D visualization API for Java and ImageJ. BMC Bioinformatics (2010) 11:274. doi:10.1186/1471-2105-11-274

38. Connor LM, Tang S-C, Camberis M, Le Gros G, Ronchese F. Helminthconditioned dendritic cells prime CD4+ T cells to IL-4 production in vivo. J Immunol (2014) 193(6):2709-17. doi:10.4049/jimmunol.1400374

39. Branzk N, Lubojemska A, Hardison SE, Wang Q, Gutierrez MG, Brown GD, et al. Neutrophils sense microbe size and selectively release neutrophil extracellular traps in response to large pathogens. Nat Immunol (2014) 15:1017-25. doi:10.1038/ni.2987

40. Branzk N, Papayannopoulos V. Molecular mechanisms regulating NETosis in infection and disease. Semin Immunopathol (2013) 35:513-30. doi:10.1007/ s00281-013-0384-6

41. Leshner M, Wang S, Lewis C, Zheng H, Chen XA, Santy L, et al. PAD4 mediated histone hypercitrullination induces heterochromatin decondensation and chromatin unfolding to form neutrophil extracellular trap-like structures. Front Immunol (2012) 3:307. doi:10.3389/fimmu.2012.00307

42. Papayannopoulos V, Metzler KD, Hakkim A, Zychlinsky A. Neutrophil elastase and myeloperoxidase regulate the formation of neutrophil extracellular traps. J Cell Biol (2010) 191:677-91. doi:10.1083/jcb.201006052

43. Blasius AL, Giurisato E, Cella M, Schreiber RD, Shaw AS, Colonna M. Bone marrow stromal cell antigen 2 is a specific marker of type I IFN-producing cells in the naive mouse, but a promiscuous cell surface antigen following IFN stimulation. JImmunol (2006) 177:3260-5. doi:10.4049/jimmunol. 177.5.3260

44. McFarlane AJ, McSorley HJ, Davidson DJ, Fitch PM, Errington C, Mackenzie KJ, et al. Enteric helminth-induced type-I interferon signalling protects against pulmonary virus infection through interaction with the microbiota. J Allergy Clin Immunol (2017) 140(4):1068.e-78.e. doi:10.1016/j. jaci.2017.01.016

45. Honda K, Yanai H, Takaoka A, Taniguchi T. Regulation of the type I IFN induction: a current view. Int Immunol (2005) 17:1367-78. doi:10.1093/ intimm/dxh318

46. McNab F, Mayer-Barber K, Sher A, Wack A, O'Garra A. Type I interferons in infectious disease. Nat Rev Immunol (2015) 15:87-103. doi:10.1038/ nri3787

47. Toshchakov V, Jones BW, Perera PY, Thomas K, Cody MJ, Zhang S, et al. TLR4, but not TLR2, mediates IFN-beta-induced STAT1alpha/beta-dependent gene expression in macrophages. Nat Immunol (2002) 3:392-8. doi:10.1038/ ni774

48. van Pesch V, Lanaya H, Renauld J-C, Michiels T. Characterization of the murine alpha interferon gene family. J Virol (2004) 78:8219-28. doi:10.1128/ JVI.78.15.8219-8228.2004

49. Swiecki M, Colonna M. The multifaceted biology of plasmacytoid dendritic cells. Nat Rev Immunol (2015) 15:471-85. doi:10.1038/nri3865

50. Asselin-Paturel C, Brizard G, Pin J-J, Brière F, Trinchieri G. Mouse strain differences in plasmacytoid dendritic cell frequency and function revealed by a novel monoclonal antibody. J Immunol (2003) 171:6466-77. doi:10.4049/ jimmunol.171.12.6466

51. Clark SR, Ma AC, Tavener SA, McDonald B, Goodarzi Z, Kelly MM, et al. Platelet TLR4 activates neutrophil extracellular traps to ensnare bacteria in septic blood. Nat Med (2007) 13:463-9. doi:10.1038/nm1565

52. Yipp BG, Petri B, Salina D, Jenne CN, Scott BN, Zbytnuik LD, et al. Infectioninduced NETosis is a dynamic process involving neutrophil multitasking in vivo. Nat Med (2012) 18:1386-93. doi:10.1038/nm.2847

53. Lindau D, Mussard J, Rabsteyn A, Ribon M, Kötter I, Igney A, et al. TLR9 independent interferon $\alpha$ production by neutrophils on NETosis in response to circulating chromatin, a key lupus autoantigen. Ann Rheum Dis (2013) 73(12):2199-207. doi:10.1136/annrheumdis-2012-203041 
54. Panda SK, Kumar S, Tupperwar NC, Vaidya T, George A, Rath S, et al. Chitohexaose activates macrophages by alternate pathway through TLR4 and blocks endotoxemia. PLoS Pathog (2012) 8:e1002717. doi:10.1371/journal. ppat. 1002717

55. Mukherjee S, Karmakar S, Babu SS. TLR2 and TLR4 mediated host immune responses in major infectious diseases: a review. Braz J Infect Dis (2016) 20:1-12. doi:10.1016/j.bjid.2015.10.011

56. Millien VO, Lu W, Shaw J, Yuan X, Mak G, Roberts L, et al. Cleavage of fibrinogen by proteinases elicits allergic responses through Toll-like receptor 4. Science (2013) 341:792-6. doi:10.1126/science.1240342

57. Bonne-Année S, Kerepesi LA, Hess JA, Wesolowski J, Paumet F, Lok JB, et al. Extracellular traps are associated with human and mouse neutrophil and macrophage mediated killing of larval Strongyloides stercoralis. Microbes Infect (2014) 16:502-11. doi:10.1016/j.micinf.2014.02.012

58. Trompette A, Divanovic S, Visintin A, Blanchard C, Hegde RS, Madan R, et al. Allergenicity resulting from functional mimicry of a toll-like receptor complex protein. Nature (2009) 457:585-8. doi:10.1038/nature07548

59. Tundup S, Srivastava L, Norberg T, Watford W, Harn D. A neoglycoconjugate containing the human milk sugar LNFPIII drives anti-inflammatory activation of antigen presenting cells in a CD14 dependent pathway. PLoS One (2015) 10(9):e0137495. doi:10.1371/journal.pone.0137495

60. Longhi MP, Trumpfheller C, Idoyaga J, Caskey M, Matos I, Kluger C, et al. Dendritic cells require a systemic type I interferon response to mature and induce CD4+ Th1 immunity with poly IC as adjuvant. J Exp Med (2009) 206:1589-602. doi:10.1084/jem.20090247

61. Blanco P, Palucka AK, Gill M, Pascual V, Banchereau J. Induction of dendritic cell differentiation by IFN-alpha in systemic lupus erythematosus. Science (2001) 294:1540-3. doi:10.1126/science.1064890

62. Trottein F, Pavelka N, Vizzardelli C, Angeli V, Zouain CS, Pelizzola M, et al. A type I IFN-dependent pathway induced by Schistosoma mansoni eggs in mouse myeloid dendritic cells generates an inflammatory signature. J Immunol (2004) 172:3011-7. doi:10.4049/jimmunol.172.5.3011

63. Yoon J, Leyva-Castillo JM, Wang G, Galand C, Oyoshi MK, Kumar L, et al. IL-23 induced in keratinocytes by endogenous TLR4 ligands polarizes dendritic cells to drive IL-22 responses to skin immunization. J Exp Med (2016) 213(10):2147-66. doi:10.1084/jem.20150376

64. Willart MA, Deswarte K, Pouliot P, Braun H, Beyaert R, Lambrecht BN, et al. Interleukin- $1 \alpha$ controls allergic sensitization to inhaled house dust mite via the epithelial release of GM-CSF and IL-33. J Exp Med (2012) 209:1505-17. doi:10.1084/jem.20112691

65. Hammad H, Chieppa M, Perros F, Willart MA, Germain RN, Lambrecht BN. House dust mite allergen induces asthma via toll-like receptor 4 triggering of airway structural cells. Nat Med (2009) 15:410-6. doi:10.1038/ nm.1946

66. Hammad H, Plantinga M, Deswarte K, Pouliot P, Willart MAM, Kool M, et al. Inflammatory dendritic cells - not basophils - are necessary and sufficient for induction of Th2 immunity to inhaled house dust mite allergen. J Exp Med (2010) 207:2097-111. doi:10.1084/jem.20101563

67. Marichal T, Bedoret D, Mesnil C, Pichavant M, Goriely S, Trottein F, et al. Interferon response factor 3 is essential for house dust mite-induced airway allergy. J Allergy Clin Immunol (2010) 126(4):836.e-44.e. doi:10.1016/j. jaci.2010.06.009

68. Taylor MJ, Cross HF, Bilo K. Inflammatory responses induced by the filarial nematode Brugia malayi are mediated by lipopolysaccharide-like activity from endosymbiotic Wolbachia bacteria. J Exp Med (2000) 191:1429-36. doi:10.1084/jem.191.8.1429

Conflict of Interest Statement: The authors declare that the research was conducted in the absence of any commercial or financial relationships that could be construed as a potential conflict of interest.

Copyright (c) 2017 Pellefigues, Tang, Schmidt, White, Lamiable, Connor, Ruedl, Dobrucki, Le Gros and Ronchese. This is an open-access article distributed under the terms of the Creative Commons Attribution License (CC BY). The use, distribution or reproduction in other forums is permitted, provided the original author(s) or licensor are credited and that the original publication in this journal is cited, in accordance with accepted academic practice. No use, distribution or reproduction is permitted which does not comply with these terms 